\title{
Decreased expression of serotonin in the jejunum and increased numbers of mast cells in the terminal ileum in patients with irritable bowel syndrome
}

\author{
Shen-Hao Wang, Lei Dong, Jin-Yan Luo, Jun Gong, Lu Li, Xiao-Lan Lu, Shui-Ping Han
}

\begin{abstract}
Shen-Hao Wang, Lei Dong, Jin-Yan Luo, Jun Gong, Lu Li, Xiao-Lan Lu, Department of Gastroenterology, Second Hospital of Xi'an Jiaotong University, Xi'an 710004, Shaanxi Province, China

Shui-Ping Han, Department of Pathology, Medical School of Xi'an Jiaotong University, Xi'an 710061, Shaanxi Province, China

Supported by the Key Clinical Project (2004) from the National Ministry of Health, No. 2004-56

Correspondence to: Professor Lei Dong, Department of Gastroenterology, Second Hospital of Xi'an Jiaotong University, 157, Xi 5 Road, Xi'an 710004, Shaanxi Province,

China. donglei4488@sina.com

Telephone: +86-29-87679272
\end{abstract}

Received: June 22, 2007 Revised: August 27, 2007

\begin{abstract}
AIM: To investigate if there are changes in serotonin (5-HT) levels, enterochromaffin (EC) cells and mast cells in small intestinal mucosa of patients with irritable bowel syndrome (IBS).

METHODS: Diarrhea-predominant (IBS-D, $n=20$ ), or constipation-predominant (IBS-C, $n=18$ ) IBS patients and healthy controls $(n=20)$ underwent colonoscopy and peroral small intestinal endoscopy, and mucosal samples were obtained at the descending part of the duodenum, proximal end of jejunum and terminal ileum. High-performance liquid chromatographyelectrochemistry and immunohistochemical methods were used to detect 5-HT content, EC cells and mast cells.
\end{abstract}

RESULTS: (1) There were no differences in the number and distribution of EC cells between IBS patients and the normal group. (2) The mucosal 5-HT contents at the duodenum, jejunum and ileum in IBS-C patients were $182 \pm 90,122 \pm 54,61 \pm 35 \mathrm{ng} / \mathrm{mg}$ protein, respectively, which were all lower than those in the normal group $(256 \pm 84,188 \pm 91$, and $93 \pm 45 \mathrm{ng} /$ $\mathrm{mg}$ protein, respectively), with a significant difference at the jejunum $(P<0.05)$. There were no differences in the small intestinal mucosal $5-\mathrm{HT}$ contents between IBS-D patients and the normal group. The mucosal 5-HT contents at the duodenum were significantly higher than those at the ileum in the three groups $(P<0.001)$. (3) The numbers of mast cells in patients with IBS-C and IBS-D at the ileum were $38.7 \pm 9.4$ and $35.8 \pm 5.5 /$ high power field (hpf), respectively, which were significantly more than that in the normal group $(29.8 \pm 4.4 / \mathrm{hpf})$ $(P<0.001)$. There was no significant difference in the numbers of mast cells at the other two parts between IBS patients and the normal group. The numbers of mast cells in IBS-C, IBS-D, and normal groups were all significantly higher at the ileum $(38.7 \pm 9.4,35.8 \pm 5.5$, $29.8 \pm 4.4 / \mathrm{hpf}$, respectively) than at the duodenum (19.6 $\pm 4.7,18.5 \pm 6.3,19.2 \pm 3.3 / \mathrm{hpf}$, respectively, $P<0.001$ ).

CONCLUSION: The changes in the $5-\mathrm{HT}$ signaling pathway at the jejunum of IBS-C patients and the increase in mast cells in patients with IBS at the terminal ileum may offer evidence to explain the pathogenesis of IBS.

(c) 2007 WJG. All rights reserved.

Key words: Enterochromaffin cell; Irritable bowel syndrome; Mast cell; Serotonin; Small intestinal mucosa

Wang SH, Dong L, Luo JY, Gong J, Li L, Lu XL, Han SP. Decreased expression of serotonin in the jejunum and increased numbers of mast cells in the terminal ileum in patients with irritable bowel syndrome. World J Gastroenterol 2007; 13(45): 6041-6047

http://www.wjgnet.com/1007-9327/13/6041.asp

\section{INTRODUCTION}

Irritable bowel syndrome (IBS) has a very high global incidence nowadays ${ }^{[1,2]}$. Though it is not fatal, it exerts a strong influence on the quality of human life $\mathrm{f}^{[3]}$. Preliminary epidemiological surveys in China had the same suggestions ${ }^{[4,5]}$.

The pathogenesis of IBS is not clear. Studies have found that alterations of many elements in the gastrointestinal mucosa serotonin (5-HT) signaling pathway occurs in IBS patients ${ }^{[6]}$, and this was one of the mechanisms for the disrupted visceral sensation and gastrointestinal motility in IBS patients. It has been shown that mast cells also play a role in the visceral hypersensitivity of IBS patients. Thus, 5-HT content in the mucosa, enterochromaffin cells (EC cells) and mast cells are the most important indicators. Thus far, many studies 
on 5-HT content, EC cells and mast cells have been carried out based on samples taken from the ileocecum, colon and rectum. It is not clear whether the small intestinal mucosa 5-HT content, EC cells and mast cells contribute to the pathological and physiological mechanism in IBS patients. The purpose of this study was to compare 5-HT content, the distribution and number of EC cells and mast cells in small intestinal mucosa in order to determine if there are changes in the 5-HT signaling pathways and mast cells in IBS patients.

\section{MATERIALS AND METHODS}

\section{Subjects}

Following the Rome III Criteria ${ }^{[7]}$, 38 IBS patients were selected as subjects, all of whom were outpatients in Department of Gastroenterology, The Second Hospital of Xi'an Jiaotong University from July 2006 to February 2007. Among them, 20 patients ( 8 male, 12 female, aged $48.7 \pm 16.6$ years) had IBS-D and 18 IBS-C (9 male, 9 female, aged $41.5 \pm 15.1$ years). These patients all underwent testing and examinations of their blood, feces, liver function and fasting blood-glucose levels. A colonoscopy and other related procedures were also performed so as to exclude organic diseases. The patients were carefully interviewed about their situations before the onset of the disease to see if they had had any attacks of acute gastroenteritis infectiosa. Those who had were regarded as post-infection IBS (PI-IBS). In this study, the number of PI-IBS samples gathered were not sufficient so they were not included in the analysis and discussion. 20 healthy people were selected as the normal group ( 9 male, 11 female, aged $39.9 \pm 19.5$ years). 5 of them underwent examinations because they were suspected of developing malignant diseases caused by familial heredity. 10 of them came to the hospital for reexamination because of intestinal polypi. 5 were volunteers. All the people in the normal group were found to be clear of a history of chronic diseases or symptoms of gastrointestinal diseases such as abdominal pain, diarrhea and constipation. Written consent was obtained from each subject. The study was approved by the Ethics Committee of the Second Hospital of Xi'an Jiaotong University and conducted according to the principle of the Declaration of Helsinki in 1995.

\section{Samples}

All the subjects stopped administering any drugs or treatments which might affect the gut movement for at least a week prior to the examinations. The first examination they had was colonoscopy (Pentex EC 3830F) and 6 pieces of mucosa from the terminal ileum, $15 \mathrm{~cm}$ from the ileocecal valve, were taken at the same time. After 1 or $2 \mathrm{~d}$ for rest, they underwent peroral small intestinal endoscopy (Fujinon EN 450P) and 12 pieces of mucosa were taken, 6 from the descending part of the duodenum, 6 from the proximal end of the jejunum, $15 \mathrm{~cm}$ from the ligament of Traitz. For each kind of piece of mucosa, 2 pieces were immediately put into $40 \mathrm{~g} / \mathrm{L}$ formaldehyde fixatives for use later in immunohistochemistry. Four pieces were put into the plastic tubes and preserved in a refrigerator at $-80^{\circ} \mathrm{C}$.

\section{Immunohistochemical staining}

The mucosa samples were paraffin-embedded in the typical manner and stained with immunohistochemicalSP. For EC cells and mast cells, rabbit anti-human 5-HT antibody (Zhongshan Jinqiao Company, Beijing, Product No. ZA-0231, dilution 1:100) and mouse antihuman tryptase antibody (Maixin_Bio Company, Fuzhou, Product No. MAB-0125, dilution 1:100) were used as primary antibodies. The secondary antibody staining kit was SP9000 of broad spectrum provided by the Zhongshan Jinqiao Company, Beijing. Next, the samples were observed under a powerful optical microscope $(X$ $400)$. Each piece of mucosa was observed continuously from 6 non-overlapping fields of view and the numbers of positive immunoreactive cells were counted, with each number expressed with "mean \pm SD".

\section{Measurement of mucosal 5-HT content}

$300 \mu \mathrm{L} 0.2 \mathrm{~mol} / \mathrm{L}$ perchloric acid containing EDTA was added to the small intestinal mucosa samples prior to homogenation. $50 \mu \mathrm{L}$ of centrifuged supernatant fluid was sent to the Xi'an Institute for Drug Control for determination of the 5-HT content with high-performance liquid chromatography-electrochemistry (HPLC-ECD), which was expressed in $\mathrm{ng} / \mathrm{mg}$ protein.

\section{Statistical analysis}

One-way analysis of variance (ANOVA) was conducted with the SPSS 13.0 software to compare 5-HT content and the number of EC cells and mast cells between the three groups. $P<0.05$ indicated significant differences.

\section{RESULTS}

\section{EC cells}

Under optical microscopy, EC cells were distributed in the intestinal gland cavity, mainly in intestinal crypts. They were next to the goblet cells and most of them were in the shape of a cone or rhombus-like. For each field of view under a powerful optical microscope $(\times 400)$, the number of EC cells at the descending part of the duodenum in patients with IBS-C and IBS-D was $9.4 \pm 3.9 /$ high power field (hpf) and $10.2 \pm 3.7 / \mathrm{hpf}$, respectively, $6.7 \pm$ $2.6 / \mathrm{hpf}$ and $6.2 \pm 2.4 / \mathrm{hpf}$ at the proximal end of the jejunum, $2.7 \pm 1.4 / \mathrm{hpf}, 3.2 \pm 1.9 / \mathrm{hpf}$ at the terminal ileum. Compared with those in the normal group (10.5 \pm $3.4 / \mathrm{hpf}, 6.6 \pm 3.4 / \mathrm{hpf}$ and $3.1 \pm 1.7 / \mathrm{hpf}$, respectively), there were no significant differences $(P>0.05$, Figure 1$)$. The distribution of EC cells in the small intestinal mucosa in patients with IBS-C and IBS-D was similar to that in the normal group, proportionately decreasing from the descending part of the duodenum to the terminal ileum. In all three groups, the number of EC cells at the descending part of the duodenum was significantly different from that at the terminal ileum $(P<0.001)$. The number of EC cells at the proximal end of the jejunum was significantly less than that at the descending part of the duodenum $(P<0.05)$ and significantly more than that at the terminal ileum $(P$ $<0.01)$. Figure 2 shows the EC cells after staining under a powerful microscope. 


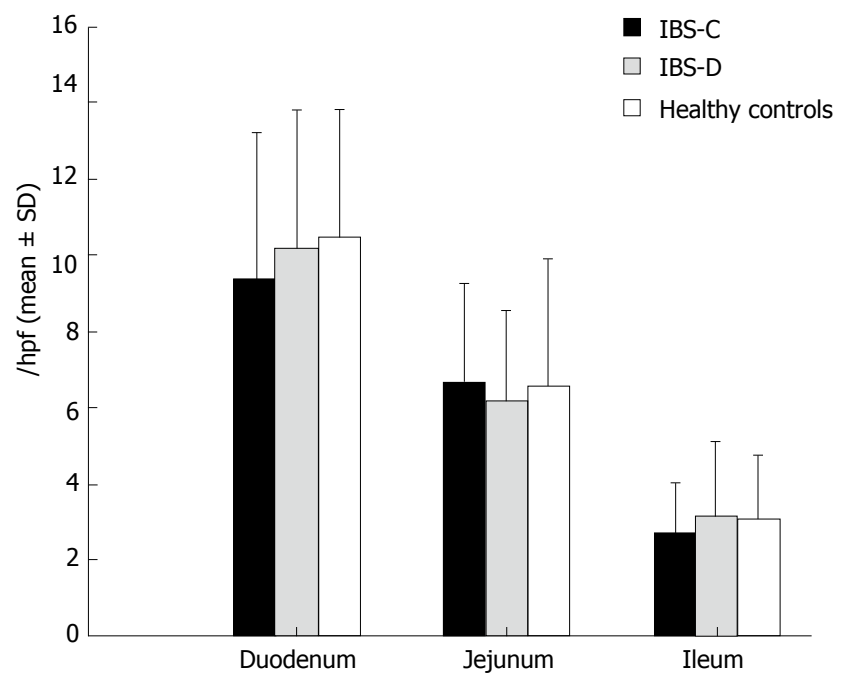

Figure 1 The number of small intestinal mucosal EC cells in IBS patients and the healthy controls. The number and distribution of EC cells in IBS patients are similar to those in the healthy controls. EC cell: Enterochromaffin cells; $5-\mathrm{HT}$ : Serotonin; IBS: Irritable bowel syndrome; IBS-C: Constipation predominant IBS; IBS-D: Diarrhea predominant IBS; hpf; High power field.

\section{5-HT content}

The 5-HT content in IBS-C patients at the descending part of the duodenum, proximal end of the jejunum and terminal ileum were $182 \pm 90 \mathrm{ng} / \mathrm{mg}$ protein, $122 \pm 54$ $\mathrm{ng} / \mathrm{mg}$ protein and $61 \pm 35 \mathrm{ng} / \mathrm{mg}$ protein, respectively, which were all lower than that in the normal group $(256 \pm 84 \mathrm{ng} / \mathrm{mg}$ protein, $188 \pm 91 \mathrm{ng} / \mathrm{mg}$ protein and $93 \pm 45 \mathrm{ng} / \mathrm{mg}$ protein, respectively). In addition, the 5-HT content at the proximal end of the jejunum had a significant difference compared with that of the normal group $(P<0.05)$. The $\mathrm{P}$ value at the descending part of the duodenum was 0.058 , and at the terminal ileum, 0.063 . The 5-HT contents in IBS-D patients at the descending part of the duodenum, proximal end of the jejunum and terminal ileum were $220 \pm 96 \mathrm{ng} / \mathrm{mg}$ protein, $167 \pm 58$ $\mathrm{ng} / \mathrm{mg}$ protein and $70 \pm 41 \mathrm{ng} / \mathrm{mg}$ protein, respectively, which were all lower than those in the normal group, but they did not show statistical significance $(P>0.05)$. Of all the three groups, the 5-HT content at the descending part of the duodenum was significantly higher than that at the terminal ileum $(P<0.001)$, with the 5 -HT content at the jejunum falling between them (Figure 3).

\section{Mast cells}

Under optical microscopy, mast cells were distributed in the lamina propria, in the shape of an egg or ellipse. They were scattered between the mucous glands with brown cytoplasm. For each field of view under a powerful optical microscope $(\times 400)$, the number of mast cells in patients with IBS-C and IBS-D at the terminal ileum were 38.7 $\pm 9.4 / \mathrm{hpf}$ and $35.8 \pm 5.5 / \mathrm{hpf}$, respectively, which were significantly more than those in the normal group (29.8 \pm $4.4 / \mathrm{hpf})(P<0.001)$. However, the numbers of mast cells in patients with IBS-C and IBS-D did not show significant differences $(P>0.05)$. The number of mast cells at the descending part of the duodenum in patients with IBS-C and IBS-D were $19.6 \pm 4.7 / \mathrm{hpf}$ and $18.5 \pm 6.3 / \mathrm{hpf}$, respectively, and $18.8 \pm 5.8 / \mathrm{hpf}$ and $19.7 \pm 4.8 / \mathrm{hpf}$ at the proximal end of the jejunum. Compared with those in the normal group $(19.2 \pm 3.3 / \mathrm{hpf}$ and $20.0 \pm 6.9 / \mathrm{hpf}$, respectively), they did not have significant differences $(P$ $>0.05$, Figure 4). The number of mast cells in the three groups at the ileum were all significantly more than those at the duodenum $(P<0.001)$. However, the numbers of mast cells at the jejunum and at the duodenum did not show significant differences $(P>0.05)$. Figure 5 shows the mast cells after staining under a powerful microscope.

\section{DISCUSSION}

The pathological mechanism of IBS is not clear ${ }^{[8]}$. It is thought that it is associated with alterations in mentality, GI motility, visceral sensitivity, etc. The abnormality in the 5 -HT content is one of the reasons for the visceral hypersensitivity and gastrointestinal dysmotility of IBS patients ${ }^{[9]}$, and the mast cells have something to do with the visceral hypersensitivity of IBS patients ${ }^{[10]}$. Because of the difficulty and trouble in taking samples from intestines, many studies on IBS so far have been based on research in mucosa from the ileocecum, colon and rectum, rather than the whole small intestine. To our knowledge, this study is a pioneering one that aims to determine the 5-HT content and number of EC cells and mast cells in the small intestinal mucosa, esp. duodenum and jejunum, in IBS patients. It is also a first study selecting subjects by following Rome III Criteria. In order to better understand the mechanism of IBS, patients were divided into two groups, i.e. patients without any attacks of acute gastroenteritis infectiosa before the onset of the disease, and those with PI-IBS, although the number was not sufficient for the analysis.

5 -HT is a very important neurotransmitter of the digestive tract; it is essential to the brain-gut connection and related to gastrointestinal motility and visceral sensation. Most of the 5-HT in the digestive tract is stored in EC cells. When EC cells are stimulated, they release 5-HT, which will act upon 5-HT receptors in intestinal nerve fibers and smooth muscle, initiate peristaltic, secretory, vasodilatory, vagal, and nociceptive reflexes, or regulate sensory function by way of vagal spinal afferent nerves. The serotonin-selective reuptake transporter (SERT) terminates the physiological function of 5-HT by taking it back up in the mucosa ${ }^{[11]}$. When studying the 5-HT signaling pathway, important elements to examine include the number of EC cells, 5-HT content, tryptophan hydroxylase level, 5-hydroxyindoleacedic acid (HIAA), plasma 5-HT concentration and SERT expression ${ }^{[12]}$. Studies on animals and humans have measured the above elements in gastric and small intestinal mucosa and drawn some meaningful conclusions with regard to the mucosa 5-HT signaling pathway ${ }^{[13-15]}$. In this study, two important indicators, EC cells and 5-HT content, were used to study the small intestinal 5-HT signaling pathway in IBS patients.

The clinical symptoms of IBS patients include abdominal pain, diarrhea and constipation. 5-HT is closely related to gastrointestinal motility and visceral sensation. Therefore, abnormalities in the 5-HT signaling pathway are regarded as the cause of visceral hypersensitivity, gastrointestinal dysmotility and parasecretion in IBS 

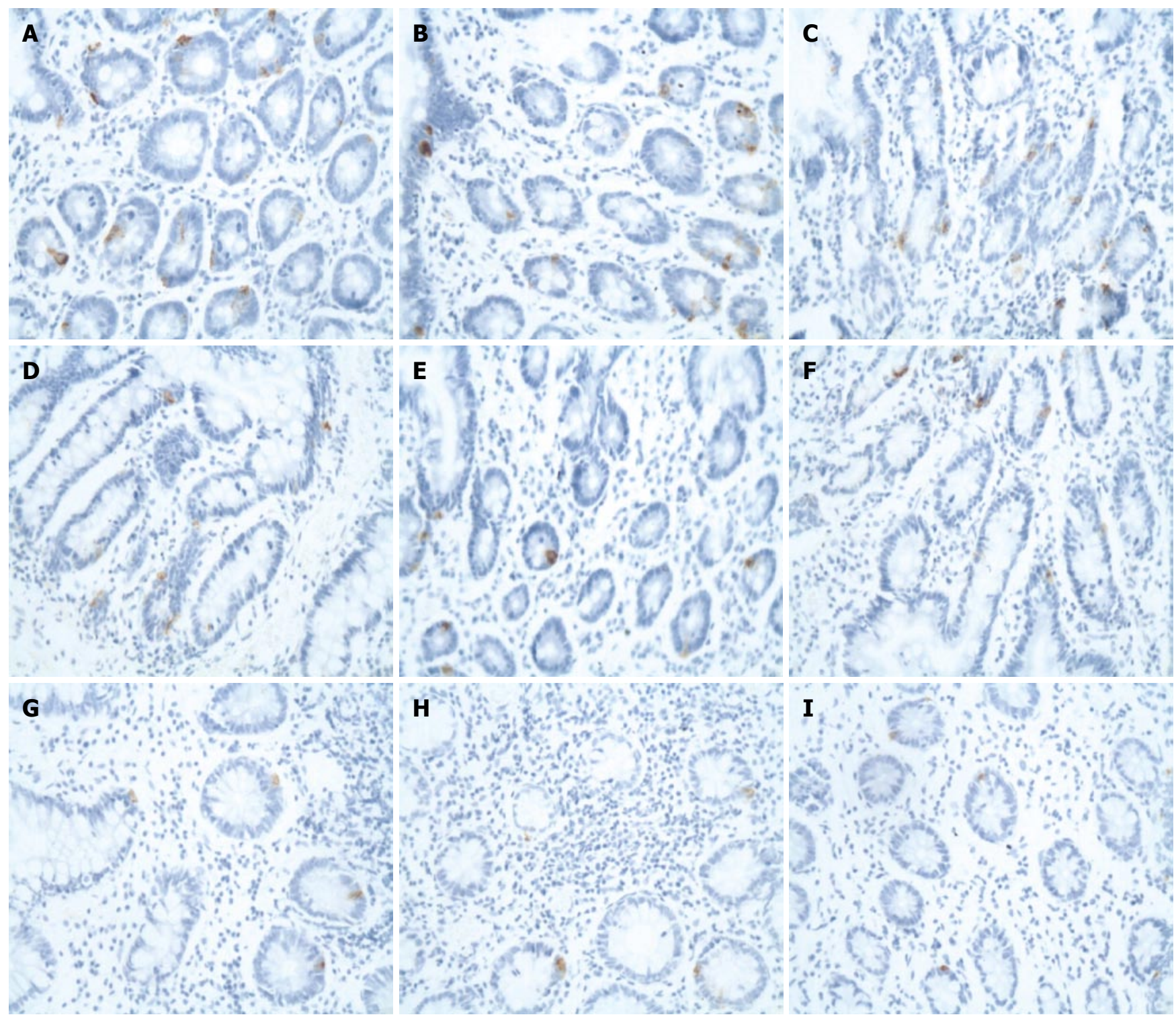

Figure 2 EC cells after being stained by rabbit anti-human 5-HT antibody under a powerful microscope $(\times 400)$. A-C: EC cells at the descending part of duodenum in healthy controls, IBS-C patients and IBS-D patients, respectively; D-F: EC cells at the proximal end of the jejunum in healthy controls, IBS-C patients and IBS-D patients, respectively; G-I: EC cells at the terminal ileum in healthy controls, IBS-C patients and IBS-D patients, respectively. EC cell: Enterochromaffin cells; 5-HT: Serotonin; IBS: Irritable bowel syndrome; IBS-C: Constipation predominant IBS; IBS-D: Diarrhea predominant IBS.

patients. A study performed by Coates $e t$ a ${ }^{[12]}$ suggested that the 5-HT signaling pathway in the mucosa of the rectum in patients with IBS-C and IBS-D had a molecular defect. However, thus far, there have been no studies on 5-HT in the whole small intestine mucosa in IBS patients.

Previous studies on 5-HT content in the colonic mucosa in IBS patients resulted in different conclusions. Coates $e t a l^{[12]}$ thought that the 5-HT content in the rectal mucosa in patients with IBS-C and IBS-D was significantly lower than that of the normal group. A study by Wang et a f $^{16}$ in China suggested that although the 5-HT content in the colonic mucosa in IBS patients was lower than that of the normal group, it did not have statistical significance. In this study, the 5-HT content in various parts of the small intestinal mucosa in IBS-C patients were all decreased, and the 5-HT content at the proximal end of the jejunum was statistically different from that in the normal group $(P<$ $0.05)$. Based on other previous studies, we propose that the decrease in 5-HT results in the weakening of various reflexes, decreasing of secretion and constipation. The fact that there was not much change in 5-HT content in the small intestinal mucosa in IBS-D patients suggested the existence of an abnormality in other 5-HT signaling pathways. Other studies draw different conclusions. Miwa et $a l^{[17]}$ thought that the increased 5-HT content in colonic mucosa in IBS-C patients relative to normal controls and IBS-D patients suggested that the synthesis of 5-HT was normal, but the release of 5-HT was changed after EC cells were stimulated.

Other studies on EC cells in IBS patients came to different conclusions. The change in EC cells in the intestinal tract in IBS patients was first found in PIIBS patients. The increase in EC cells was regarded as a characteristic change in PI-IBS patients ${ }^{[18-20]}$, but it was not applied to IBS patients who had had no infection before the onset of the disease. Studies made by Dunlop 


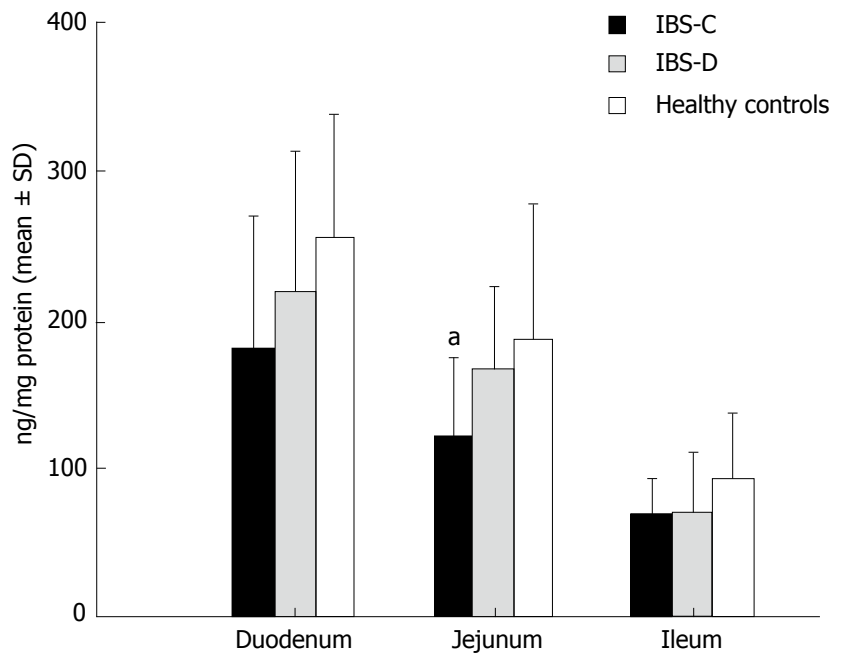

Figure 3 The content of small intestinal mucosal 5-HT in IBS patients and the healthy controls. For each part, the 5-HT content in the IBS-C patients is lower than that in the healthy controls. The 5-HT content at the proximal end of jejunum shows a significant difference compared with that in the normal group $(P<0.05)$. The 5-HT content in the three groups at the descending part of duodenum are all significantly higher than that at the terminal ileum $(P<0.001) .{ }^{\mathrm{a}} P<0.05$ vs healthy controls. EC cell: Enterochromaffin cells; 5 -HT: Serotonin; IBS: Irritable bowel syndrome; IBS-C: Constipation predominant IBS; IBS-D: Diarrhea predominant IBS

et a ${ }^{[18,19]}$ and Spiller et al ${ }^{[20]}$ found no increase in EC cells in IBS patients with no infection before the onset of the disease. Coates et al ${ }^{[12]}$ thought that there was no change in the number of EC cells in the rectal mucosa in patients with IBS-C and IBS-D. Li et $a l^{[21]}$ and Jiang et al ${ }^{[22]}$ found that the number of EC cells at the junction of the rectum and sigmoid colon in patients with IBS-C and IBS-D significantly increased, but in the ileocecum it did not. In this study, the number and distribution of EC cells in the small intestinal mucosa in IBS patients did not show significant differences compared with those in the normal group, which suggested there were no obvious pathological changes in the EC cells in the small intestinal mucosa in IBS patients.

Looking at the small intestinal mucosa 5-HT content and the distribution and number of EC cells in IBS patients, we found that the 5-HT content decreased but the number of EC cells remained unchanged compared with that in the normal group, which suggested that the amount of 5-HT released by EC cells in the small intestinal mucosa in IBS-C patients was less than that in the normal group. In IBS-D patients, the 5-HT content and number of EC cells remained the same as those in the normal group, suggesting a difference in 5-HT signaling pathways in IBS-C and IBS-D patients.

Studies have shown that mast cells have something to do with the visceral hypersensitivity of IBS patients ${ }^{[23]}$. Many agents released by mucosa mast cells can affect intestinal nerve and smooth muscle. Experiments on animals and studies in human beings all proved that mast cells and intestinal nerves are closely connected ${ }^{[24]}$, and in IBS patients, the connection was even closer $^{[25]}$. The increase of mast cells in IBS patients results in more agents being released by mast cells. All these, together with

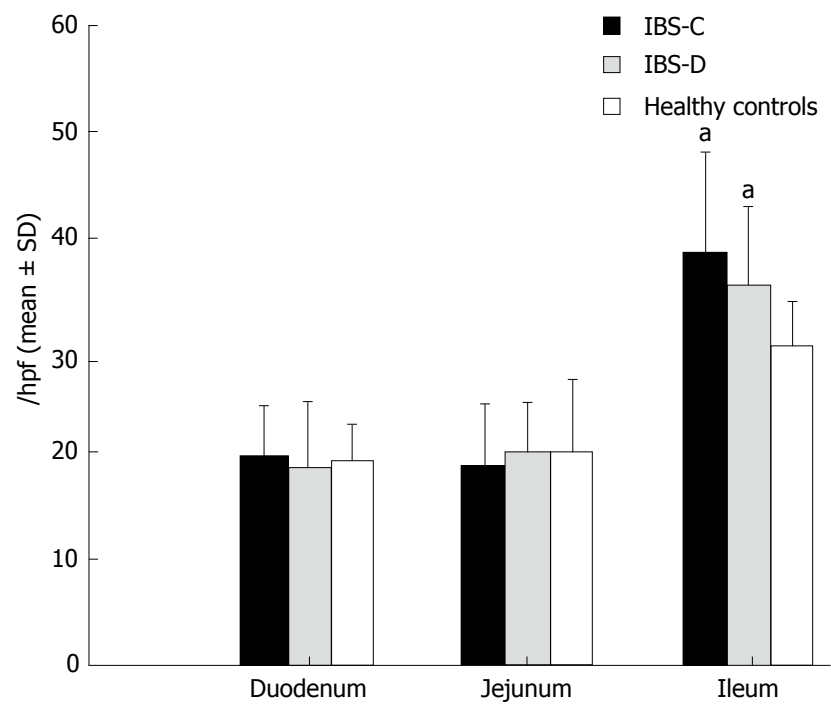

Figure 4 The number of small intestinal mucosal mast cells in IBS patients and the healthy controls. The number of mast cells at the terminal ileum in patients with IBS is significantly different compared with that in the healthy controls $(P<0.001)$. The numbers of mast cells in patients with IBS-C and IBS-D at the other two parts of the intestine do not have significant differences, compared with those in the healthy controls $(P>0.05) .{ }^{a} P<0.05$ vs healthy controls. EC cell: Enterochromaffin cells; 5-HT: Serotonin; IBS: Irritable bowel syndrome; IBS-C: Constipation predominant IBS; IBS-D: Diarrhea predominant IBS; hpf: High power field.

the close connection between the mast cells and nerve fibers, contribute to the seriousness of abdominal pain.

Many studies have demonstrated that the increase of mast cells in the ileocecum is a characteristic change of $\operatorname{IBS}^{[23,26,27]}$. Park et al ${ }^{[23]}$, Dong et a ${ }^{[26]}$ and Chen et a ${ }^{[27]}$ found an increased number of mast cells in the ileocecum mucosa in IBS patients. Meanwhile, studies suggested the ileocecum might be the site of origin for abdominal pain, bloating, and changes in bowel habits, showing more sensitivity when a balloon dilates ${ }^{[28]}$. In this study, the number of mast cells at the terminal ileum in IBS patients increased significantly compared with that of the normal group, which is in line with the conclusions drawn from previous studies. It is indicated that the change of mast cell number in the terminal ileum in IBS patients is the characteristic pathological change. Studies on mast cells in other parts of the colonic mucosa (except the cecum) in IBS patients have produced different conclusions. Some found an increase in the number of mast cells ${ }^{[18,23,26]}$, while others did not ${ }^{[19,26]}$. So far, in China, there have been no studies on mast cells in the duodenum and jejunum in IBS patients. In this study, the numbers of mast cells in the duodenum and jejunum in patients with IBS-C and IBS-D were almost the same as that in the normal group. This study also revealed that the distribution of mast cells in small intestinal mucosa in IBS patients was the same as that in the normal group, i.e. gradually increasing from the duodenum to the ileum.

In conclusion, this study reveals, for the first time, a change in the 5-HT signaling pathway in the jejunum in patients with IBS-C. It also suggests that the increase of mast cells in the ileocecum is the characteristic pathological change in IBS patients. These changes in the mucosa of gastrointestinal tract cause IBS-related symptoms. This 

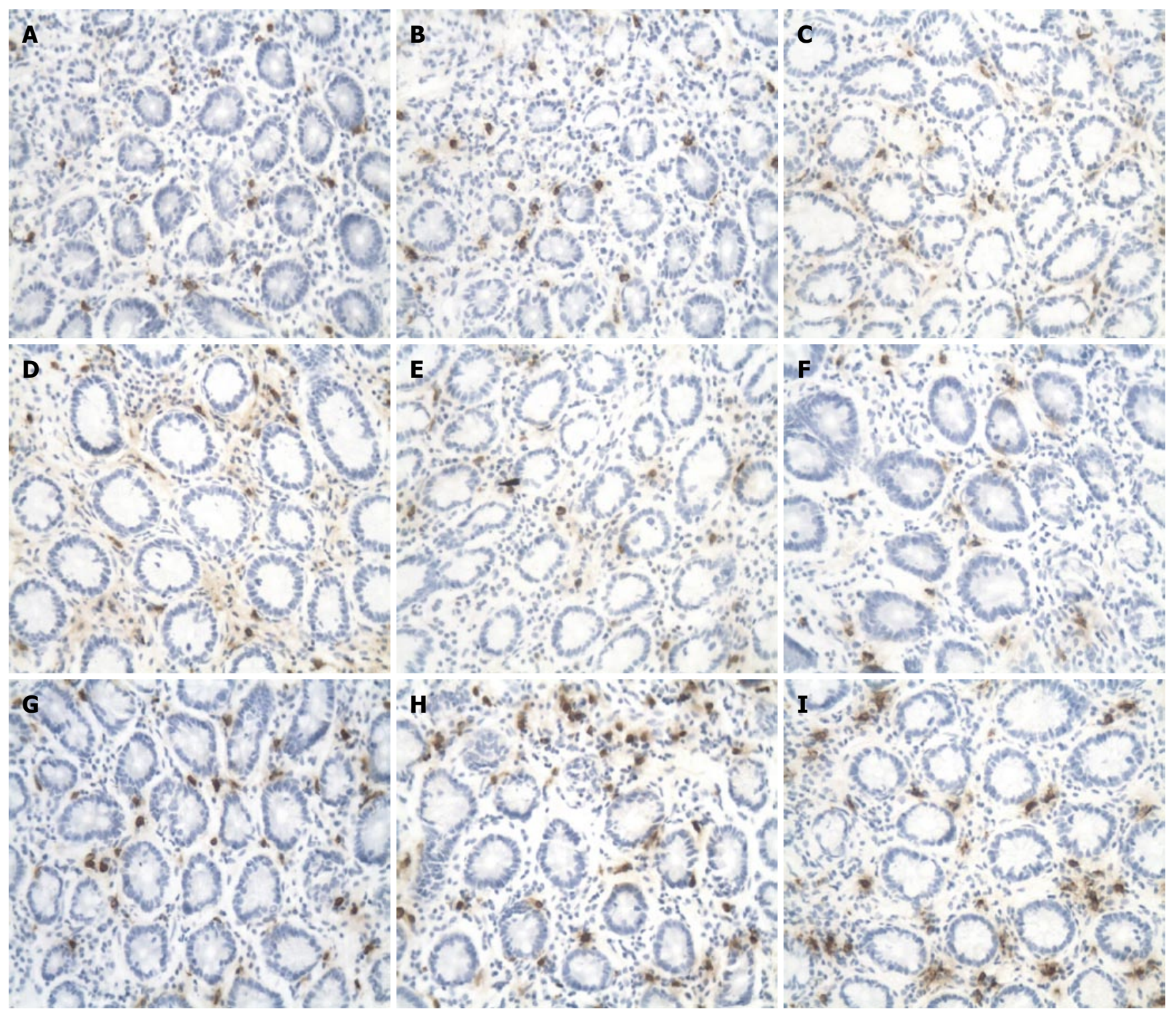

Figure 5 Mast cells after staining by mouse anti-human tryptase antibody under a powerful microscope $(\times 400)$. A-C: Mast cells at the descending part of the duodenum in healthy controls, IBS-C patients and IBS-D patients, respectively; D-F: Mast cells at the proximal end of jejunum in healthy controls, IBS-C patients and IBS-D patients respectively; G-I: Mast cells at the terminal ileum in healthy controls, IBS-C patients and IBS-D patients, respectively. EC cell: Enterochromaffin cells; 5-HT: Serotonin; IBS: Irritable bowel syndrome; IBS-C: Constipation predominant IBS; IBS-D: Diarrhea predominant IBS.

study offers new insight that may be useful for further research into the pathogenesis of IBS.

\section{COMMENTS}

\section{Background}

Studies have found that abnormal serotonin $(5-\mathrm{HT})$ levels and mast cells are two of the reasons for the disturbance of visceral sensation and gastrointestinal motility in patients with irritable bowel syndrome (IBS). Many studies on 5-HT contents, enterochromaffin (EC) cells and mast cells in IBS have been carried out based on samples taken from mucosa from the ileocecum, colon and rectum, rather than in the whole small intestine.

\section{Research frontiers}

The purpose of this study was to compare $5-\mathrm{HT}$ content, the distribution and number of EC cells and mast cells in small intestinal mucosa in order to determine if there were changes in 5-HT signaling pathways and mast cells in small intestinal mucosa in IBS patients.

\section{Innovations and breakthroughs}

(1) This study is the first one, to our knowledge, to determine the 5-HT contents,
EC cells and mast cells in the small intestinal mucosa, especially the duodenum and jejunum, in IBS patients. (2) It is also the first study on the selection of subjects following Rome III Criteria. (3) In order to better understand the mechanism of IBS, patients were divided into two groups; i.e. patients without any attack of acute gastroenteritis infectiosa before the onset of IBS and patients with previous gastrointestinal $(\mathrm{GI})$ infections (post-infection IBS or PI-IBS) although, they could not be used as a group for the analysis due to the small number of cases.

\section{Applications}

These changes of 5-HT signaling pathway and mast cells in mucosa of the Gl tract will cause IBS-related symptoms. This study offers new insight towards further research into the pathogenesis of IBS.

\section{Terminology}

Visceral hypersensitivity: When the GI tract is stimulated by luminal distention and other stimuli, perception of abdominal pain or discomfort is increased. This is widely regarded as the reason for the development of functional gastrointestinal diseases, including functional dyspepsia and irritable bowel syndrome. 5-HT signaling pathways: This refers to the whole process including 5 -HT release in the $\mathrm{Gl}$ tract and central nervous system, binding to its receptors, re-uptake and degradation. Elements involved in the study of the 5 -HT signaling pathway include determination of the number of EC cells, $5-\mathrm{HT}$ content, tryptophan hydroxylase 
level, 5-hydroxyindoleacedic acid (HIAA), plasma 5-HT concentration and serotonin-selective reuptake transporter (SERT) expression.

\section{Peer review}

The study is of interest and permits a better understanding of IBS. It shows that the changes of $5-\mathrm{HT}$ signaling pathway at the jejunum of IBS-C patients and the increase of mast cells in patients with IBS at ileocecum may offer evidence to explain the pathogenesis of IBS.

\section{REFERENCES}

1 Drossman DA, Camilleri M, Mayer EA, Whitehead WE. AGA technical review on irritable bowel syndrome. Gastroenterology 2002; 123: 2108-2131

2 Han SH, Lee OY, Bae SC, Lee SH, Chang YK, Yang SY, Yoon BC, Choi HS, Hahm JS, Lee MH, Lee DH, Kim TH. Prevalence of irritable bowel syndrome in Korea: population-based survey using the Rome II criteria. J Gastroenterol Hepatol 2006; 21: 1687-1692

3 Paré P, Gray J, Lam S, Balshaw R, Khorasheh S, Barbeau M, Kelly S, McBurney CR. Health-related quality of life, work productivity, and health care resource utilization of subjects with irritable bowel syndrome: baseline results from LOGIC (Longitudinal Outcomes Study of Gastrointestinal Symptoms in Canada), a naturalistic study. Clin Ther 2006; 28: 1726-1735; discussion 1710-1711

4 Lau EM, Chan FK, Ziea ET, Chan CS, Wu JC, Sung JJ. Epidemiology of irritable bowel syndrome in Chinese. Dig Dis Sci 2002; 47: 2621-2624

5 Si JM, Chen SJ, Sun LM. An epidemiological and quality of life study of irritable bowel syndrome in Zhejiang province. Zhonghua Neike Zazhi 2003; 42: 34-37

6 Mawe GM, Coates MD, Moses PL. Review article: intestinal serotonin signalling in irritable bowel syndrome. Aliment Pharmacol Ther 2006; 23: 1067-1076

7 Longstreth GF, Thompson WG, Chey WD, Houghton LA, Mearin F, Spiller RC. Functional bowel disorders. Gastroenterology 2006; 130: 1480-1491

8 Harris LA, Chang L. Irritable bowel syndrome: new and emerging therapies. Curr Opin Gastroenterol 2006; 22: 128-135

9 Gershon MD. Nerves, reflexes, and the enteric nervous system: pathogenesis of the irritable bowel syndrome. J Clin Gastroenterol 2005; 39: S184-S193

10 Barbara G, Stanghellini V, De Giorgio R, Corinaldesi R. Functional gastrointestinal disorders and mast cells: implications for therapy. Neurogastroenterol Motil 2006; 18: 6-17

11 Crowell MD. Role of serotonin in the pathophysiology of the irritable bowel syndrome. Br J Pharmacol 2004; 141: 1285-1293

12 Coates MD, Mahoney CR, Linden DR, Sampson JE, Chen J, Blaszyk H, Crowell MD, Sharkey KA, Gershon MD, Mawe GM, Moses PL. Molecular defects in mucosal serotonin content and decreased serotonin reuptake transporter in ulcerative colitis and irritable bowel syndrome. Gastroenterology 2004; 126: $1657-1664$

13 Bian X, Patel B, Dai X, Galligan JJ, Swain G. High mucosal serotonin availability in neonatal guinea pig ileum is associated with low serotonin transporter expression. Gastroenterology

\section{7; 132: 2438-2447}

14 van Lelyveld N, Ter Linde J, Schipper ME, Samsom M. Regional differences in expression of TPH-1, SERT, 5-HT(3) and 5-HT(4) receptors in the human stomach and duodenum. Neurogastroenterol Motil 2007; 19: 342-348

15 Liu H, Irving HR, Tan YY, Meng L, Chetty N, Coupar IM. Influences of gender and region on responses to 5-HT in the rat small intestine. Pharmacology 2004; 72: 220-224

16 Wang ZJ, Ouyang Q, Zou YG, Peng L, Wang YF. Comparison of intestinal mucosal monamine neurotransmitter of ulcerative colitis and irritable bowel syndrome. Zhonghua Neike Zazhi 2005; 11: 851-852

17 Miwa J, Echizen H, Matsueda K, Umeda N. Patients with constipation-predominant irritable bowel syndrome (IBS) may have elevated serotonin concentrations in colonic mucosa as compared with diarrhea-predominant patients and subjects with normal bowel habits. Digestion 2001; 63: 188-194

18 Dunlop SP, Jenkins D, Spiller RC. Distinctive clinical, psychological, and histological features of postinfective irritable bowel syndrome. Am J Gastroenterol 2003; 98: 1578-1583

19 Dunlop SP, Jenkins D, Neal KR, Spiller RC. Relative importance of enterochromaffin cell hyperplasia, anxiety, and depression in postinfectious IBS. Gastroenterology 2003; 125: 1651-1659

20 Spiller RC, Jenkins D, Thornley JP, Hebden JM, Wright T, Skinner M, Neal KR. Increased rectal mucosal enteroendocrine cells, T lymphocytes, and increased gut permeability following acute Campylobacter enteritis and in post-dysenteric irritable bowel syndrome. Gut 2000; 47: 804-811

21 Li ZS, Zhan LX, Zou DW, Xu GM, Man XH, Ye XT. Morphological and functional alteration of serotonin-producing intestinal enterochromaff in cells in patients with irritable bowe syndrome. Zhonghua Xiaohua Zazhi 2004; 24: 94-97

22 Jiang M, Lin LP, Fu BY. Distribution feature of colonic 5-HT in irritable bowel syndrome. Shijie Huaren Xiaohua Zazhi 2005; 13. 541-543

23 Park JH, Rhee PL, Kim HS, Lee JH, Kim YH, Kim JJ, Rhee JC. Mucosal mast cell counts correlate with visceral hypersensitivity in patients with diarrhea predominant irritable bowel syndrome. J Gastroenterol Hepatol 2006; 21: 71-78

24 Stead RH. Innervation of mucosal immune cells in the gastrointestinal tract. Reg Immunol 1992; 4: 91-99

25 Barbara G, Stanghellini V, De Giorgio R, Cremon C, Cottrell GS, Santini D, Pasquinelli G, Morselli-Labate AM, Grady EF, Bunnett NW, Collins SM, Corinaldesi R. Activated mast cells in proximity to colonic nerves correlate with abdominal pain in irritable bowel syndrome. Gastroenterology 2004; 126: 693-702

26 Dong WZ, Li ZS, Zou DW, Xu GM, Zou XP, Zhu AY, Yin N, Gong YF. The changes of mucosal mast cells and substance $\mathrm{P}$ in patients with irritable bowel syndrome. Zhonghua Neike Zazhi 2003; 42: 611-614

27 Chen WK, Zou YY, Li FJ, Luo D. Changes of psychosocial factors, enteric mucosal mast cells and 5-hydroxytryptamine in irritable bowel syndrome. Shijie Huaren Xiaohua Zazhi 2007, 15: $46-50$

28 Phillips SF, Camilleri M. The ileocecal area and the irritable bowel syndrome. Gastroenterol Clin North Am 1991; 20: 297-311

S- Editor Zhu LH L- Editor Alpini GD E- Editor Li HY 